Provincial Infectious Diseases Advisory Committee on Infection Prevention and Control (PIDAC-IPC). Antimicrobial surfaces to prevent healthcare- associated infections: a systematic review. J Hosp Infect 2015;92:7-13.

3. Lynne M. Sehulster. Healthcare laundry and textiles in the United States: review and commentary on contemporary infection prevention issues. Infect Control Hosp Epidemiol 2016;36: 1073-1088.

4. Weinstein RA. Intensive care unit environments and the fecal patina: a simple problem? Crit Care Med 2012;40:1333-1334.

\section{Tourniquet Contamination in Helicopter Emergency Medicine Services in Germany}

To the Editor-Problems with infection control policies regarding tourniquets, such as visible bloodstains and contamination with methicillin-resistant Staphylococcus aureus, have been reported in the past ${ }^{1}$ and colonization of reusable tourniquets with multidrug-resistant organisms has been discussed as a potential source of transmission in hospitalized patients. ${ }^{2}$

As part of our quality assurance program we assessed the reprocessing procedure and the bacterial contamination load on reusable tourniquets at 23 helicopter stations of the German Helicopter Emergency Medical Services operated by DRF Luftrettung gAG.

The tourniquet in use during the day was collected at the end of the shift (from sunrise to sundown) and sampled with RODAC (replicate organism detection and counting) plates, and a questionnaire about its use and reprocessing standards was distributed and collected. RODAC plates were used in accordance with microbiology procedure quality standards $s^{3}$ and results are given in colony-forming units per RODAC plate.

Table 1 shows the results for the 21 data sets that were included in the final analysis; 2 data sets could not be used because in one case the tourniquet could not be sampled and in one case the questionnaire was incomplete.

We did not find any multidrug-resistant organisms although the helicopters are frequently used for interhospital transfer of critically ill patients colonized with multidrugresistant organisms; however, tourniquets are rarely used for these patients. Colonized tourniquets showed mostly regular environmental and skin organisms in low to moderate numbers. Only one sample had 200 colony-forming units of coagulase-negative staphylococci and 5 samples showed 1-5 colony-forming units of mold. There was no correlation between duration of use, mode of storage, or frequency of use and the total count of colony-forming units. Reprocessing protocols were heterogeneous, with most stations using disinfection wipes after each use. The best microbiologic results were observed in stations using disinfection wipes after every use and daily machine washing at $60^{\circ} \mathrm{C}$.

Leitch et $\mathrm{al}^{4}$ reported contamination with methicillin-resistant S. aureus of tourniquets of phlebotomists but also observed lapses in hand hygiene compliance. They observed no change in tourniquet contamination when polyurethane strips were used as an additional barrier and concluded that the contamination of tourniquets is via phlebotomists' hands and not directly from patient's skin. This could explain why we mostly found normal environmental and skin flora in our probes despite partially inadequate and nonstandardized reprocessing practices. The out-of-hospital emergency medicine setting might also be different from the inpatient setting, where studies frequently show contamination of tourniquets with $S$. aureus and methicillinresistant $S$. aureus but also lack of standardization of cleaning procedures of the used tourniquets. ${ }^{5}$

In conclusion, tourniquets used in the German Helicopter Emergency Medical Services do not seem to be a relevant vector of transmission of pathogenic or multidrug-resistant organisms. However, there is potential for improvement and a need for standardization of cleaning procedures after use. A combination of using disinfecting wipes after each use and daily machine washing at $60^{\circ} \mathrm{C}$ seems to yield the best results.

\section{ACKNOWLEDGMENTS}

Financial support. None reported.

Potential conflicts of interest. S.S.-S. reports that he is co-owner of the Deutsches Beratungszentrum für Hygiene and receives royalties for book publishing from Springer and Schattauer publishers, Germany. J.H. reports no conflicts of interest relevant to this article.

\section{Sebastian Schulz-Stübner, MD, PhD; ${ }^{1}$ Jürgen Henker, Koordinator Hygienemanagement Medizin $^{2}$}

Affiliations: 1. Deutsches Beratungszentrum für Hygiene, Freiburg im Breisgau, Germany; 2. DRF Stiftung Luftrettung gemeinnützige AG, Filderstadt, Germany.

Address correspondence to Sebastian Schulz-Stübner, MD, PhD, Deutsches Beratungszentrum für Hygiene, Schnewlinstr. 1079098 Freiburg im Breisgau, Germany (schulz-stuebner@bzh-freiburg.de).

Infect Control Hosp Epidemiol 2016;37:1262-1264

(C) 2016 by The Society for Healthcare Epidemiology of America. All rights reserved. 0899-823X/2016/3710-0024. DOI: 10.1017/ice.2016.183

\section{REFERENCES}

1. Rourke C, Bates C, Read RC. Poor hospital infection control practice in venipuncture and use of tourniquets. J Hosp Infect 2001;49:59-61.

2. Pinto AN, Phan T, Sala G, Cheong EY, Siarakas S, Gottlieb T. Reusable venesection tourniquets: a potential source of hospital transmission of multiresistant organisms. Med J Aust 2011;195: 276-278. 


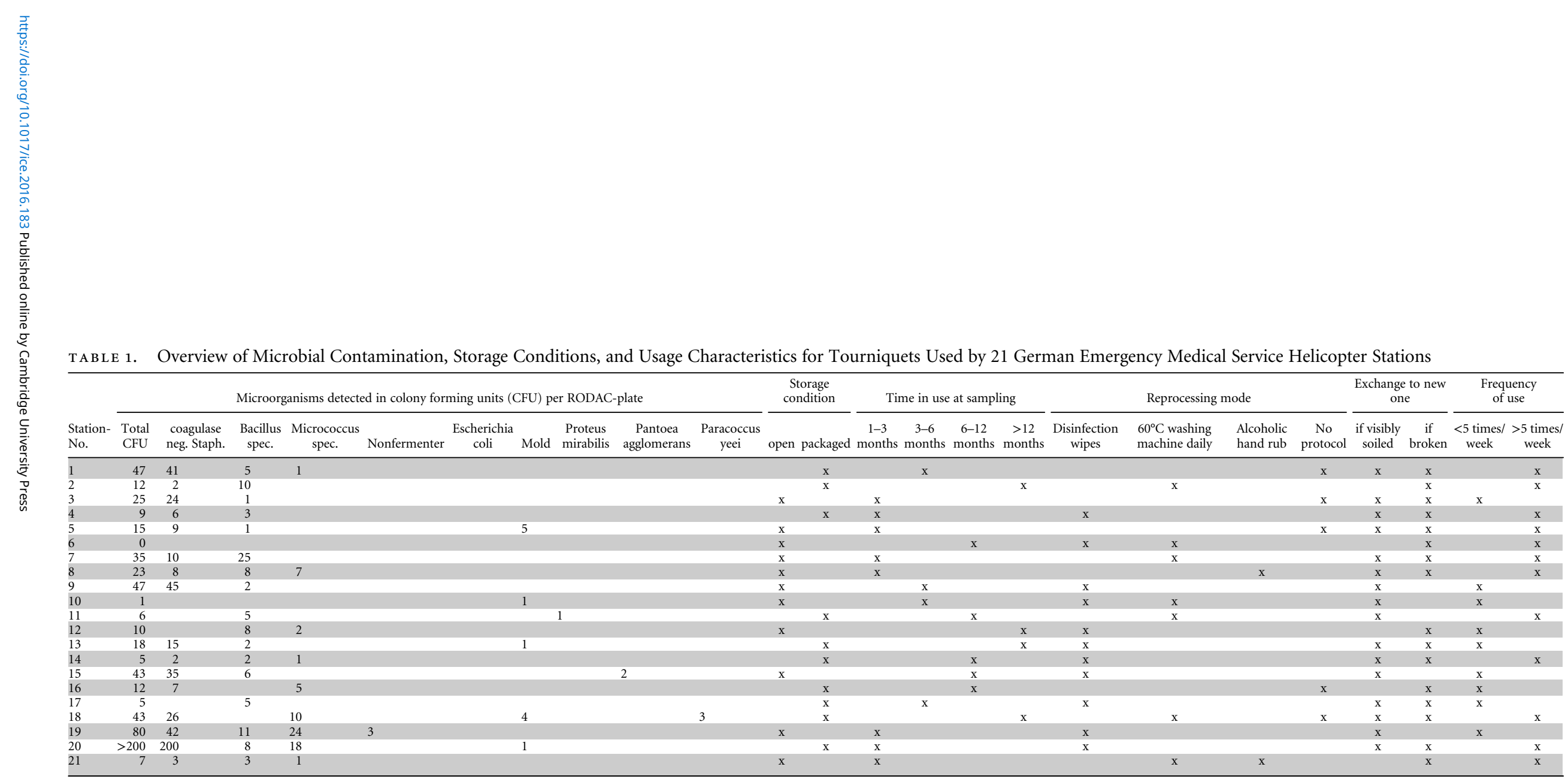

NOTE. RODAC, replicate organism detection and counting. 
3. Podbielski A, Herrmann M, Kniehl E, Mauch H, Rüssmann H, eds. MiQ: Qualitätsstandards in der mikrobiologisch-infektiologischen Diagnostik. München: Elsevier; 2007.

4. Leitch A, Mc Cromick I, Gunn I, Gillespie T. Reducing the potential for phlebotomy tourniquets to act as a reservoir for methicillin-resistant Staphylococcus aureus. J Hosp Infect 2006; 63:428-431.

5. Mehmood Z, Mubeen SM, Afzal MS, Hussain Z. Potential risk of cross-infection by tourniquets: a need for effective control practices in Pakistan. Int J Prev Med 2014;9:1119-1124. 